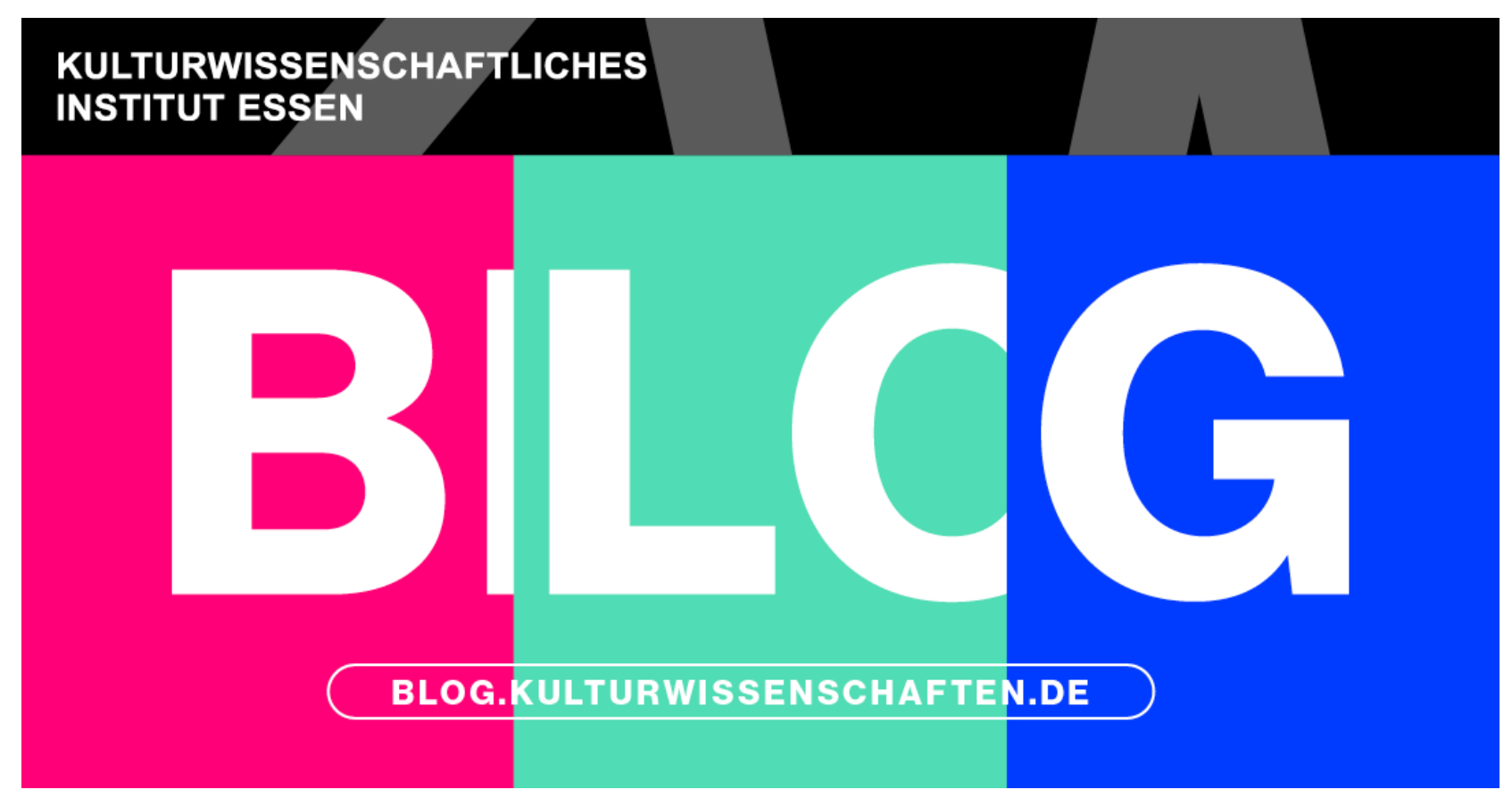

\title{
A Break from the News? The Decameron Project and Short Fiction in Times of Fear
}

Erschienen in: ANGST + | FEAR + Von: Sage Anderson

In the summer of 2020, anxiously perusing the New York Times digital edition one morning, I was delighted to come upon The Decameron Project amid otherwise bleak headlines. Published by the New York Times Magazine as an all-fiction issue, this project consists of new short stories by 29 writers, accompanied by illustrations from various artists. In the preface to the print edition published that fall, editor Catherine Roper describes the trajectory of the project based on contemporary interest in the original Decameron, written by Giovanni Boccaccio in mid- $14^{\text {th }}$-century Italy. ${ }^{1}$ For me, the trajectory was reversed; it was after discovering The Decameron Project that I started reading Boccaccio's work during the (first?) lockdown winter of the Covid-19 pandemic. ${ }^{2}$ When I finished, I was left thinking about both of these collections of short fiction in relation to the fearful news of the day. 


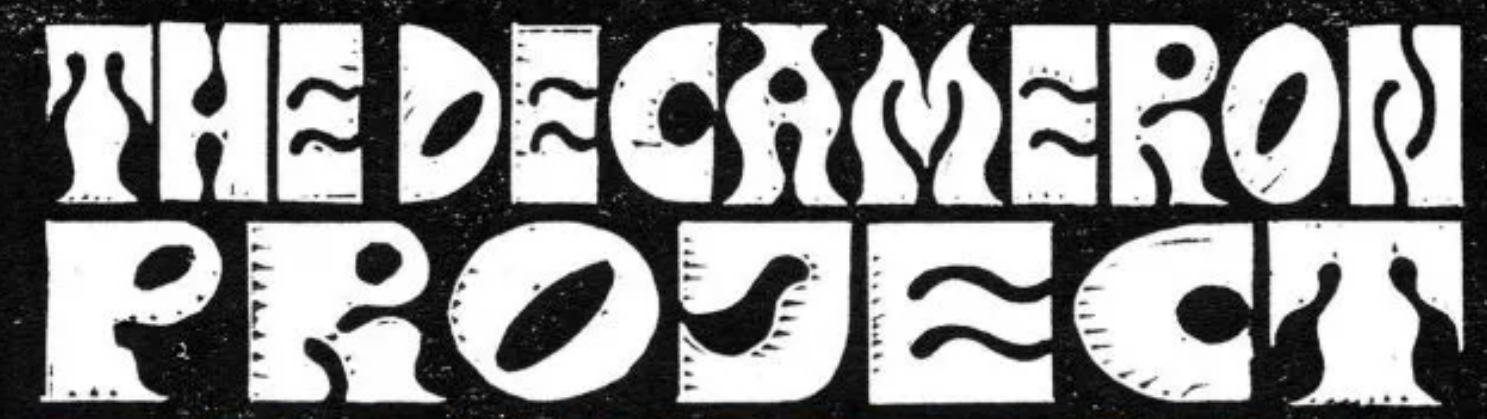

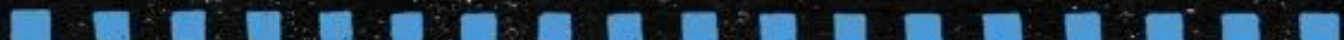

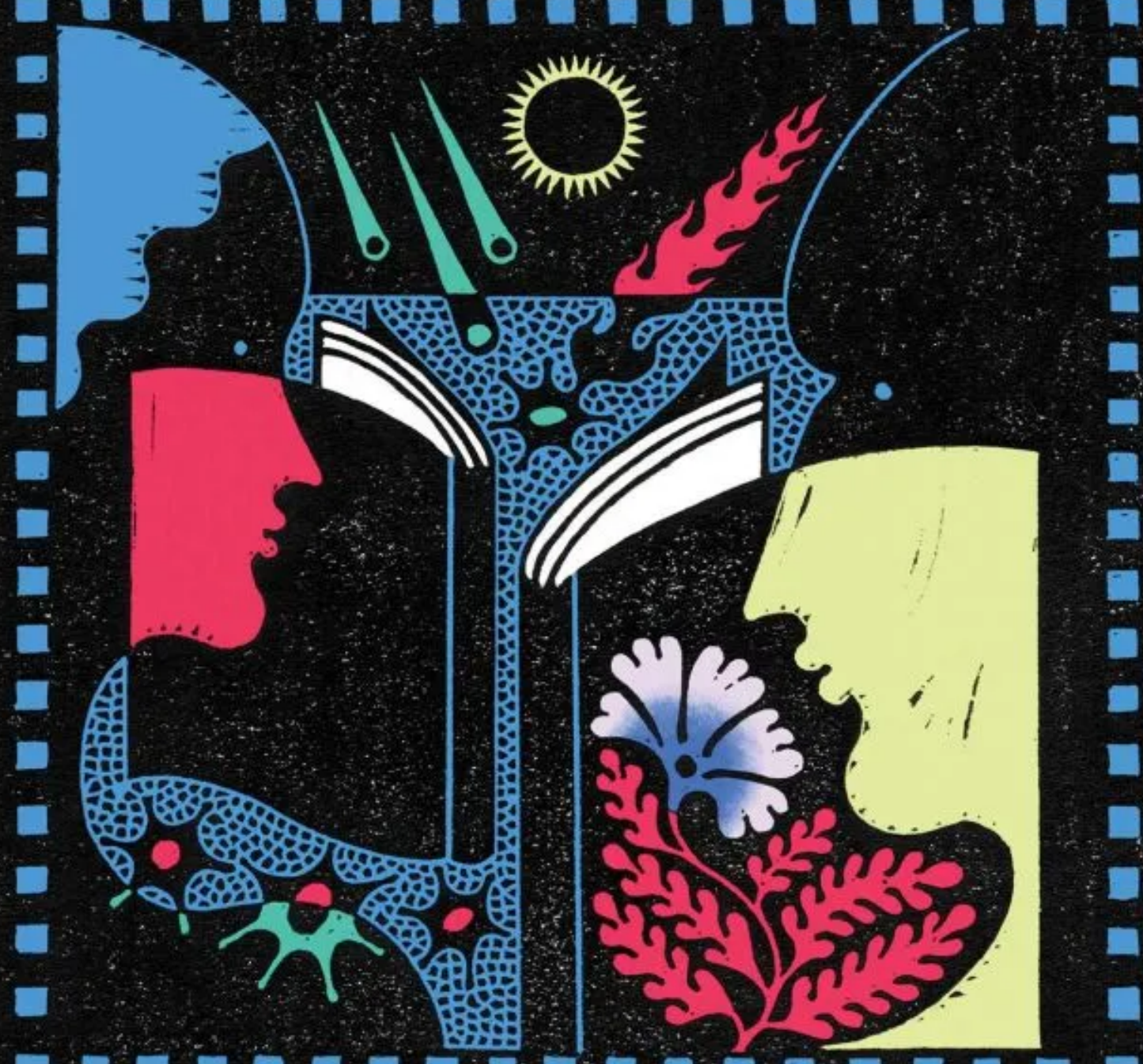

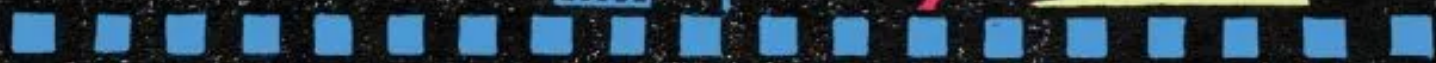

R9

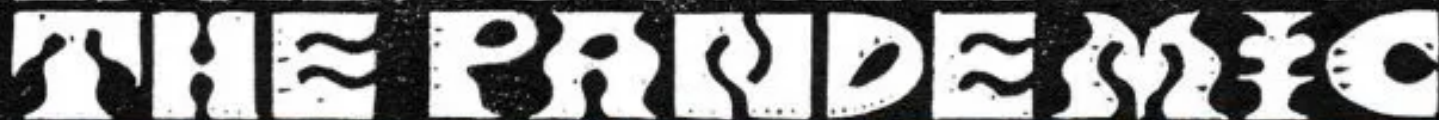
Wล

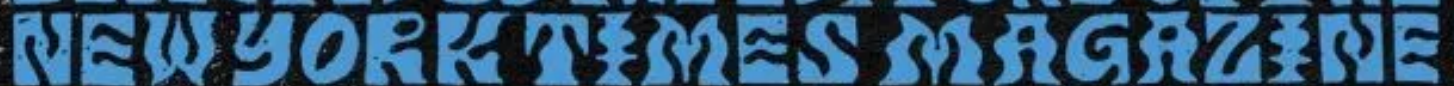


What happens when fiction is explicitly situated in relation to the news of distressing current events? These days, many of us find ourselves in a situation where reading about what is happening around us is an essential component of our everyday experience, itself involving a great deal of fear. Even in the domestic arena presently deemed most safe, the spaces where news reaches us have become fraught with fear through daily encounters with endless links, headlines, images, and articles heralding constantly multiplying threats. While this is nothing new, and by no means limited to the Covid-19 pandemic, the increased seclusion and particular media landscape of the past 1.5 years have provided a breeding ground for anxious fixation on the reporting of negative events, and the related phenomenon of "doomscrolling." 3

In Boccaccio's Decameron, a group of rich friends escape plague-ridden Florence for their own safety, relinquishing any responsibility for others. ${ }^{4}$ The work begins with an account of the plague, and as it appeared shortly after the 1348 outbreak, it did constitute a source of information for contemporaries. ${ }^{5}$ Yet Boccaccio takes his characters out of the city precisely in order to remove them from bad news. Ten lucky characters, seven women and three men, spend ten days not fearing the Black Death because they are busy telling each other stories while lounging in beautiful settings, waited on by servants. The idea comes from Pampinea, and as the group's organizer, her first act is to command the servants "to take care that, no matter what they see or hear in their comings and goings, no news from the outside world should ever reach us unless that news is good" (Boccaccio, 21). In this way, the ten friends seal their pod, to borrow a term from the current pandemic. For them, this means blocking out any bad news - not a problem thanks to their servants. Averting their eyes from the "outside world," they create an inside world where the only news comes from the stories being told. ${ }^{6}$ Boccaccio thus offers escape for his protagonists as well as distraction for his readers: fictionally as well as IRL, storytelling serves as a salubrious means of passing the time. ${ }^{7}$ The 100 stories have a wide range of themes - often incredibly smutty and/or offensive - and a huge cast of characters, but one thing they have in common is that they are not about the plague. Many of them present frightful scenarios with moral lessons, but none of them engage directly with the ongoing devastation left behind in Florence.

The Decameron Project has a very different relationship to the news, beginning with its setting in a major international news platform. Linked to the New York Times, the homepage for the digital edition opens with an animated image situated at the top of an interactive story portal. The heading reads: "When reality is surreal, only fiction can make sense of it." Arriving on this page takes you into an immersive realm - and yet, the point is not to leave the news behind, at least not entirely, or for very long. ${ }^{8}$ One major difference from Boccaccio's work is that the stories of The Decameron Project come from individual authors, differing widely in perspective and style. Yet the majority of stories are set in the present, many of them in New York City, and most of them engage more or less explicitly with the pandemic. ${ }^{9}$

However, engaging with the news through fiction does not mean entering into the realtime flow of events. To zero in on one example, take the story "Line 19 Woodstock/Glisan," by Karen Russell. This story is set in Portland, Oregon, in the present 
of the current pandemic. Narrated in the third person, the story revolves around Valerie, who drives the 19 bus (surely no coincidence). This job is difficult at the best of times, and the pandemic adds further layers of justified anxiety. As she drives her nighttime route, Valerie is thinking about her worries and reflecting on her regular passengers - "the Last Bus Club" (Decameron Project, 146) - when suddenly an ambulance veers into the wrong lane on a bridge, heading full speed toward the bus. The story begins: "It happened just like people said: Time really did slow down" (145). For now, the reader is safe to assume that this is just a common metaphor for the perception of time in moments of crisis. Valerie hits the breaks, it seems as if a crash is inevitable, and then the bus comes to a stop "with an otherworldly shrieking, a breath away from the ambulance's grille. Valerie waited for a wave of relief that never came. Needlessly, she applied the emergency brake. The clock had frozen at 8:48 p.m." (148). Even here, there is no reason to suspect anything other than the realistic portrayal of a narrowly avoided traffic accident, but it soon becomes clear that something more profound has taken place.

As everyone gets off the bus, they realize that time has actually stopped, as reflected in the lack of passing headlights, the stillness of the river below, and the strangeness of the surrounding light. Valerie tries to radio for help, with no response: "She hadn't really expected an answer. What surprised her was the speed with which her confusion turned into horror, her horror into a stupefied resignation. There was no use struggling against the facts: The 19 was lost in Time" (150). Just like that, the reader is suspended in surreality along with the passengers. Valerie quickly realizes what has been lost along with the passage of time, namely the ability to return to her elderly mother - who has had a stroke - and her teenage son, and this puts all of her previous fears into a new perspective: "She felt a stab of nostalgia for the anxieties of 8:47 p.m." (151). After some panic, the group comes to the realization that it is up to them to get time moving. One of the passengers - Fatima, a nurse who delivers babies - sees what needs to be done: "'Listen, I don't know why I didn't think of this before. We are stuck in the canyon between $8: 48$ and 8:49. This happens during birth, sometimes. And fear shuts everything down'" (154). To get out of this canyon - and over this fear - Fatima positions everyone around the bus to push and tells them to sing, breathing together and chanting, so that things will open up again. It takes a great effort, but slowly, the wheels begin to roll (155). Bonded by the collective experience, they are all relieved, and Valerie starts the bus and begins to drive away:

The clock clicked over to 8:49. [...] It felt almost like a numb foot coming awake. As she drove, constellations of moments began to kaleidoscope through Val's body, painful and sharp - her mother lying on the floor, the white knife of [her son's] birth, Freddie laughing tears over scalding coffee, the smell of smoldering rubber, her years coiling like circuitry. Now she could see the real lights of her city: the haloed lobbies of the condominiums, the skeletal boats in the harbor. Tent camps and vacant hotels, butterflied around the river. The world they'd left was the one they returned to: trembling, rain-wet, lush, trashed, alive (157). 
Returning to time means returning to the city, in all of its living dimensions; a bus provides no means of escape from this world, even after time has briefly stopped. Only now, through the experience of the near crash, the members of the Last Bus Club know that the horror of being stuck in time - or perhaps outside of time - is far worse than the anxieties of the everyday, even in an ongoing pandemic. With this in mind, the reader may be able to look up to see today's headlines already fading into the past, and while this does not mean that tomorrow's news will be any better, it does serve as a powerful reminder that life exceeds the fearful present moment. Among other things, this is what fiction can do - especially when the next story is only a click/page away.

\section{References}

1. The New York Times Magazine (2020): The Decameron Project: 29 New Stories from the Pandemic, New York/London, Scribner, pp. vii-ix.

2. Boccaccio, Giovanni (2013): The Decameron, translated and with an introduction by Wayne A. Rebhorn, New York, Norton. This work won Rebhorn the prestigious PEN America Literary Award for Translation in 2014.

3. Doomscrolling or Doomsurfing is defined on Wikipedia as "the act of spending an excessive amount of screen time devoted to the absorption of negative news," and this definition is followed by a warning: "Increased consumption of predominantly negative news may result in harmful psychophysiological responses in some." (https://en.wikipedia.org/wiki/Doomscrolling)

4. For further reflections on The Decameron and the moves made by the rich to distance themselves from fear and exposure, see the June $2020 \mathrm{KWI}$ blog article "Auf Distanz gehen. Über Angst und Reichtum" [https://blog.kulturwissenschaften.de/auf-distanz-gehen/] by Armin Flender.

5. The book was written between 1349 and 1352 and it opens with a description of the plague. Noting that Boccaccio relied in part on sources long predating events in Florence, Rebhorn places more significance on Boccaccio's insightful account of the pandemic's destructive impact on social order. See introduction (Decameron, $x x v i i i-x x l, x x x v i-x l v)$.

6. Rebhorn articulates an etymological relationship between storytelling and the news: "it makes perfect sense for the group of storytellers to find their own new solution to the problems the plague has produced, and it is especially fitting that their central activity is to tell stories, for 'stories' in Italian is novelle, a word that derives from nuovo, 'new,' and that always has some sense that the story involved is new, different, unexpected, a notion enshrined as well in the idea of the 'news'" (Decameron, xlii). 
7. Boccaccio frames the characters' decision to tell each other stories in terms of pleasure and health (Decameron, 22-23). In terms similar to my reading, Elisabeth Bronfen interprets Boccaccio's work as a timeout from fear in the chapter "Literarische Auszeit" of her 2020 book Angesteckt. Zeitgemässes über Pandemie und Kultur. Bronfen further explores the relationship between fiction and the news by juxtaposing significant news stories with interpretations of films and literary works that engage with themes of infection and disease. Jill Lepore looks at many of the same pandemic narratives in her March 2020 New Yorker article, "What Our Contagion Fables Are Really About." Lepore's interpretation focuses on "the contagion of reading" itself as at once infection and antidote (https://www.newyorker.com/magazine/2020/03/30/what-our-contagion-fables-arereally-about).

8. During the Covid-19 pandemic, the New York Times started offering a "break from the news" at the bottom of its daily briefing, with sections on culture, cooking, entertainment, and wellness. This often generated jarring juxtapositions between headlines and images of upheaval and death with images of curated plates of impeccably prepared food, presented as if in an aesthetic vacuum. Significantly, especially in light of this prominent daily feature (since relabled), The Decameron Project was not presented as a break from the news.

9. Only one of the stories - "Impatient Griselda," by Margaret Atwood - is an explicit play on Boccaccio's work, specifically the final story of The Decameron, but even this story takes a radical leap: it is set among aliens sent to Earth to provide pandemic aid.

SUGGESTED CITATION: Anderson, Sage: A Break from the News? The Decameron Project and Short Fiction in Times of Fear, in: KWI-BLOG, [https://blog.kulturwissenschaften.de/a-break-from-the-news/], 22.11.2021

DOI: https://doi.org/10.37189/kwi-blog/20211122-0830 


\section{DuEPublico}

This text is made available via DuEPublico, the institutional repository of the University of Duisburg-Essen. This version may eventually differ from another version distributed by a commercial publisher.

DOI: $\quad 10.37189 / \mathrm{kwi}-\mathrm{blog} / 20211122-0830$

URN: urn:nbn:de:hbz:464-20211122-100645-8 